A First Course in Applied Electronics 
Other titles in Electrical and Electronic Engineering

J. C. Cluley: Electronic Equipment Reliability

B. A. Gregory: An Introduction to Electrical Instrumentation

Paul A. Lynn: An Introduction to the Analysis and Processing of Signals

A. G. Martin and F. W. Stephenson: Linear Microelectronic Systems

A. Potton: An Introduction to Digital Logic

J. T. Wallmark and L. G. Carlstedt: Field-Effect Transistors in Integrated Circuits

G. Williams: An Introduction to Electrical Circuit Theory 


\section{A First Course in Applied Electronics}

An Introduction to Microelectronic Systems

\section{W. Gosling}

Professor of Electronic Engineering University of Bath 
All rights reserved. No part of this publication may be reproduced or transmitted, in any form or by any means, without permission

First published 1975 by THE MACMILLAN PRESS LTD London and Basingstoke Associated companies in New York Dublin Melbourne Johannesburg and Madras

SBN 333171748

ISBN 978-1-349-02362-2 ISBN 978-1-349-02360-8 (eBook) DOI 10.1007/978-1-349-02360-8

The paperback edition of this book is sold subject to the condition that it shall not, by way of trade or otherwise, be lent, re-sold, hired out, or otherwise circulated without the publisher's prior consent in any form of binding or cover other than that in which it is published and without a similar condition including this condition being imposed on the subsequent purchaser. 


\section{Contents}

Preface $\quad$ ix

1 Introduction to Electronics 1

1.1 Systems and Parts 1

1.2 Integrated Circuits 2

1.3 Integrated Circuit Fabrication Technologies 3

1.4 Amplifiers - General 4

2 Fundamental Principles of Amplification 8

2.1 Introduction 8

2.2 Controlled Energy Conversion $\quad 8$

2.3 Controlled Variable Dissipation Devices 9

2.4 Switching Amplifiers 13

2.5 Negative Resistance Amplifiers $\quad 15$

2.6 Parametric Amplifiers 17

2.7 The Different Kinds of Amplifier Reviewed 18

3 More about Amplifiers 21

3.1 Equivalent Circuits 21

3.2 The Norton Form 25

3.3 Frequency Response 26

3.4 The Bel 28

3.5 Frequency-Response Plots 29

3.6 Other Causes of Falling High-Frequency Output 33

3.7 Low-Frequency Effects 35

3.8 Narrow-band Amplifiers $\quad 37$

3.9 Signal-Handling Capacity 41 
3.10 Working-Point and Biasing 42

3.11 Amplifier Terminology and Symbolic Diagrams 47

4 Unwanted Outputs 52

4.1 Introduction 52

4.2 Sources and Types of Noise 52

4.3 Specifying Amplifier Noise 55

4.4 Drift 57

5 Feedback $\quad 59$

5.1 Introduction 59

5.2 Series Voltage Feedback 63

5.2.1 Series voltage feedback with real loop gain 66

5.2.2 Series voltage feedback with complex loop gain 70

5.3 Other Feedback Configurations 73

5.3.1 Series current feedback $\quad 73$

5.3.2 Shunt feedback 76

5.4 Feedback: A Recapitulation 78

6 Feedback in Practice 82

$\begin{array}{lll}6.1 & \text { Introduction } & 82\end{array}$

6.2 Trading Gain for Band-width 82

6.3 Oscillation and Trigger Circuits 86

6.4 Trigger Circuits in Practice 88

6.5 Sinusoidal Oscillators 91

6.6 Feedback and Unwanted Signals 92

6.7 Feedback and Distortion 93

6.8 Working-Point Stabilization 96

7 Feedback Problems 100

7.1 Negative into Positive Feedback 100

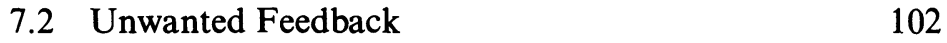

8 Integrated Amplifiers 106

8.1 The Economic Ground Rules 106

8.2 Bipolar Transistor Amplifiers 109

8.2.1 Special circuit configurations 112

8.3 A Simple Integrated Amplifier 118 
8.4 The 741-A Sophisticated Operational Amplifier 121 8.4.1 Characteristics of the 741

8.5 Some Other Integrated Amplifiers $\quad 126$

8.6 Packaging the Integrating Amplifier 129

9 Some Practical Examples 132

9.1 Introduction 132

9.2 The 741 as an Inverting Amplifier 134

9.3 The 741 as a Non-inverting Amplifier 135

9.4 Raising the Input Impedance 138

9.5 Raising the Available Output Power 140

9.6 Narrow-band Amplifier and Active Filters 144

9.7 A Monostable Multivibrator 146

9.8 A Sinusoidal Oscillator 148

Answers to question $\quad 151$

Index 159 


\section{Preface}

Some years ago the author prepared a book intended to be a first textbook on applied electronics for undergraduates. The project arose from a widespread feeling that, as a result of the introduction of microcircuits, a new approach was required to elementary electronics teaching.

Over the last quarter of a century the approach to teaching had settled down to a standardized form, based on electronic physics as its starting point. Thus quantum mechanical theory of solids played a central role and most electronics textbooks began with an elementary introduction to this subject. Thereafter it was normal to progress to a treatment of the physical properties of the electronic device, particularly bipolar transistors. Only at that point did it become possible to discuss the applications of devices in typical circuits such as are in everyday use.

Though this approach to teaching the subject was admirable in some ways, it suffered from the defect that it placed the emphasis primarily on the physics of electrical devices and only to a much lesser extent on their applications, yet it was the latter which formed the primary motivation of study in most cases.

With the introduction of microcircuits, the path from quantum physics to useful applications becomes very long indeed. Electronics specialists, and particularly those who hope to design integrated circuits themselves, will naturally have to pursue the subject back to its physical origins. There will be many, however, including the majority of professional engineers concerned with using electronics, to whom the physical processes occurring within the microcircuits will be a matter of much less importance. For them the fundamental starting point will be the terminal properties of the integrated circuit, and they will be concerned with its effective application in complicated electronic systems. 
Thus it seemed right to try to design a course which regarded the properties of the microcircuit as the basic starting point. As far as digital circuits are concerned, it is the integrated logic blocks which are primitive and a number of excellent textbooks are now available for students which take this as their starting point. By contrast, for linear systems the fundamental building block is of course the amplifier. Thus amplifiers form the starting point for a microcircuitoriented linear-electronics course.

The original book was well received, and was adopted as a teaching text in a number of institutions, but like all pioneer efforts it suffered from certain inadequacies, and in particular was rather oversimplified in some sections. The present volume is a result of a very thorough reconstruction of the original text, based upon the advice received from many teachers and students, and it is confidently believed that the defects unavoidable in a first attempt at a new approach to teaching have now been eliminated. The author owes a tremendous debt of gratitude to the very many colleagues all over the world who were so kind as to write to him welcoming the book, and giving constructive criticisms and suggestions for its revision. It is a pleasure to acknowledge the contribution made by many friends in universities and polytechnics, because without their help it is doubtful whether this experiment in electronics teaching could have gone any further. It is to be hoped that they will feel that their comments have resulted in the production of the book they were so obviously looking for.

In addition to providing a first-year course for electronics students (by whom it will be used in conjunction with elementary texts on circuit theory and physical electronics), it is believed that this book will be of value for non-electronics specialists, in physics, chemistry and the biological sciences, who require an operational knowledge of applied electronics as part of their professional equipment. Since the prerequisite of this book excludes physics and consists only of mathematics (up to elementary calculus) and a simple knowledge of electrical-circuit theory (up to complex-number representations), most such students will be able to use it effectively.

Finally I should like to express my thanks to Mrs Carolyn Scantlebury, who typed the manuscript. 